\title{
Influence of the Cyclic Loading Path on Rock Deformation Memory Effect
}

\author{
Lingwei Zhong, ${ }^{1}$ Haijun Wang $\mathbb{D}^{2,3}$ Xuhua Ren, ${ }^{1,4}$ and Lei Tang ${ }^{2}$ \\ ${ }^{1}$ College of Water Conservancy and Hydropower Engineering, Hohai University, Nanjing, China \\ ${ }^{2}$ Nanjing Hydraulic Research Institute, Nanjing, China \\ ${ }^{3}$ State Key Laboratory of Hydrology-Water Resources and Hydraulic Engineering, Hohai University, Nanjing, China \\ ${ }^{4}$ Collaborative Innovation Center on Water Safety and Water Science, Hohai University, Nanjing, China \\ Correspondence should be addressed to Haijun Wang; hjwang@nhri.cn
}

Received 22 September 2020; Revised 24 October 2020; Accepted 28 October 2020; Published 24 November 2020

Academic Editor: Hongyu Wang

Copyright @ 2020 Lingwei Zhong et al. This is an open access article distributed under the Creative Commons Attribution License, which permits unrestricted use, distribution, and reproduction in any medium, provided the original work is properly cited.

\begin{abstract}
Deformation rate analysis utilizes deformation memory effect (DME) that is one of the fundamental properties of rock, to estimate in situ stress underground. It could be influenced by the stress history which has been subjected to in the past. To understand the influence under the cyclic loading path, in the experimental study, different stress levels were applied on sandstone samples and two types of granite samples. In the theoretical investigation, the sliding friction model consisting of multiple microstructure surfaces is considered in this paper. Both experiments and the theoretical model show that when the number of cyclic loading times keeps increasing, (1) the stress read at the DRA inflection is getting closer to the previously cyclic stress; (2) the angle at the DRA inflection becomes sharper, which gives clearer inflection point; and (3) the strain differential amplitude in the DRA curve gradually decreases and then toward a stable value. An upper limit exists for influence, indicating that the best cyclic loading times occur when the pulse amplitude of the strain differential stops changing. It is confirmed that the multiple cyclic loading method provides a better outcome for experiment using artificial preload when DME is utilized for stress reconstruction. Without other factors disturbing, the memory information of the in situ stress would hardly lose under the history of cyclic loading.
\end{abstract}

\section{Introduction}

Materials such as rock, concrete, and metals are proved to be characterized by storing the information of the external influences previously imposed on them (loading and temperature) and reading such information through the deformation and strain data process, namely, the deformation memory effect (DME) [1-3]. The rock DME is a generally proved property $[4,5]$. For example, in a uniaxial cyclic compression test, the gradient of strain differential-stress curve of the rock sample will change if the subsequent loading stress surpasses the maximum previous loading stress. The information about the maximum previous loading stress may be observed from the deflection point in the strain difference-stress curve, which is called the rock deformation memory. The mechanical properties of rock mass have declined under the influence of longterm weathering and rainfall $[6,7]$. The initial in situ stress which is formed under the long-term action of the rock mass is the fundamental force for the failure of the rock underground engineering. The measurement of the initial in situ stress is currently the most important engineering application of DME. The deformation rate analysis (DRA) method [2] is to read the initial in situ stress memory information obtained from the rock core test in the laboratory on the basis of the rock DME in situ stress memory effect.

Using different methods of forming memory information, we have artificial memory (formed via indoor and artificial loading) and in situ stress memory (subject to a longterm geological process). Artificial DME, one of the basic approaches of rock DME study, is to implant explicit memory information into the rock samples by indoor preloading for the memory variation research. This approach is employed because the absolute value of the initial in situ stress is unknown, and thus, the results from the memory measurement lack confirmation [2-4]. The indoor artificial loading method mainly includes single loading, cyclic 
loading, and creeping loading. When studying the relation between the rock DME and ultrasonic at the Taiheiyo minefield, Goto et al. [8] utilized cyclic loading at a strain rate of $1.5 * 10^{-5} / \mathrm{s}$ to construct the memory information, including 10 times for $20 \mathrm{MPa}$ cycle, 5 times for $35 \mathrm{MPa}$ cycle, and $50 \mathrm{MPa}$ cycle for each test. In the course of the crustal stress measurement at McArthur River and Kundana minefield in Australia, Seto et al. [9] performed 10 times of cyclic loading with a loading rate of $0.1 \mathrm{MPa} / \mathrm{s}$ and a peak of $10 \mathrm{MPa}$ in order to investigate the rock memory properties at the minefield. In addition, the results were compared with those from the CSIRO's HI cell method. When investigating how the outdoor exposure duration ( 1 hour, 1 day, 7 days, and 30 days, respectively) influences the rock DME, Park et al. [10] performed 10 times of cyclic loading on Hwangdung rock samples so as to construct $20 \mathrm{MPa}$ memory information. As Shimada et al. [11] implemented the crustal stress at the Ikeshima colliery region with the DRA method, they took 5 times of 17.4 MPa cycle on tuff samples. When Soma et al. [12] measured the crustal stress at the Tono minefield, 5 times of $5 \mathrm{MPa}$ cycle were applied for the DME research. Attar et al. [13] firstly analyzed the DME features of shallow brittle rock and ductile rocks sampled from zones with different stress levels $(10 \%, 14 \%$, and $56 \%$ of UCS), wherein $3-4$ times of cyclic loading were utilized to construct the memory information. Also, in the research on the memories of pelitic schist in the Hualien region and sandstone in the Changchi layer at Zengwun Dam, up to 500-1000 times of cyclic loading were performed to construct the memory information $[14,15]$. Lin et al. [16] also adopted the cyclic loading pattern to construct the memory information.

However, current research on DME under the cyclic path basically focuses on the physical experiments and engineering applications, while there are less researches on the formation mechanism and theoretical model of rock DME, especially the theoretical research on the rock DME formation mechanism under the cyclic loading path. As the macroscopic behaviors of rock are determined by mechanical behaviors of rock matrix and microstructures [17-19], the rock DME is also caused by the mechanical behaviors of microstructure influencing the DME. In addition, the mechanical behaviors of rock microstructure are closely associated with the rock deformation and damage processes, which consists of five phases in the case of uniaxial compression: crack closure, elasticity, crack generation and propagation, unstable crack propagation, and postdamage or postpeak softening phase [20], as shown in Figure 1.

In the early study of DME, Yamamoto et al. [2] and Tamaki et al. [21] predicted that the DME mechanism existed due to the generation and propagation of microcracks within the rock. As such, they believed that no DME existed in low-stress zones such as the crack closure and elasticity zone and conducted their study based on the shear crack model proposed by Kuwahara et al. [22]. Some researchers such as Seto et al. [23] and Villaescusa et al. [24] adopted this model during the DME application. Hunt et al. [25] adopted commercial software PFC2D to perform the DME simulation based on the crack propagation model. However, as indicated by Yamshchikov et al. [1], the crack model proposed by
Kuwahara et al. [22] may not explain many DME features such as memory losing, while it still needs further discussion whether this model can be proved to be the DME formation mechanism through Hunt et al. [25] fitting partial test data by adjusting the commercial software parameters. In addition, "no DME exists in low stress zones below the initial stress value of the micro crack" concluded by Hunt et al. [25] on the basis of crack propagation model contradicts the results of physical tests performed by Wang et al. [26] who concluded that the rock DME still exists in low-stress zones through indoor and artificial DME experiments in low-stress zones with sandstone. As to this concern, Wang et al. [27] proposed a sliding friction model which answered the question why DME exists in five stress phases under uniaxial rock compression and suggested that friction sliding behaviors always exist on the microstructure surfaces, along with nonlinear deformation and friction hysteresis [28, 29] even if the stresses are lower than crack initiation stress.

In summary, existing literature of the rock DME predominantly focuses on the cyclic loading path and may determine that the cyclic loading has a positive impact on the construction of rock memory information. However, the following questions still need to be addressed:

(1) Why does the cyclic loading path act on the rock DME and what is the mechanism behind? How could we model its mechanical theory and can we explain its influence following the theoretical model based on sliding friction?

(2) What are the specific features of influences that the cyclic loading path has on the rock DME property and the DRA method?

(3) What is the determination standard of the best precyclic loading times? Would it be better if more cycles are performed, like 500-1000 times as stated in the reference?

As to the questions above, the aim of this paper is to go through an indoor and artificial DME physical test under the cyclic loading path. Based on the friction sliding hysteresis and the energy transferring mechanism between the elastic matrix and viscous media, a theoretical model of the three-rock-element memory element is built, and the mechanism of cyclic loading path influence on rock DME is studied.

\section{Rock DME and DRA Method}

Rock DME refers to a property of obtaining the rock memory information through analyzing its deformation information. The deformation rate analysis (DRA) was proposed by Yamamoto et al. [2] and is used for the DME memory information measurement. Dotted lines shown in Figure 2 represent the external stresses forming the memory information $\left(\sigma_{p}\right), m$ represents a number of loading times used for forming the memory information, and the solid line represents successively repeating two times of cyclic loading in the laboratory to obtain the stress and strain data for reading the 


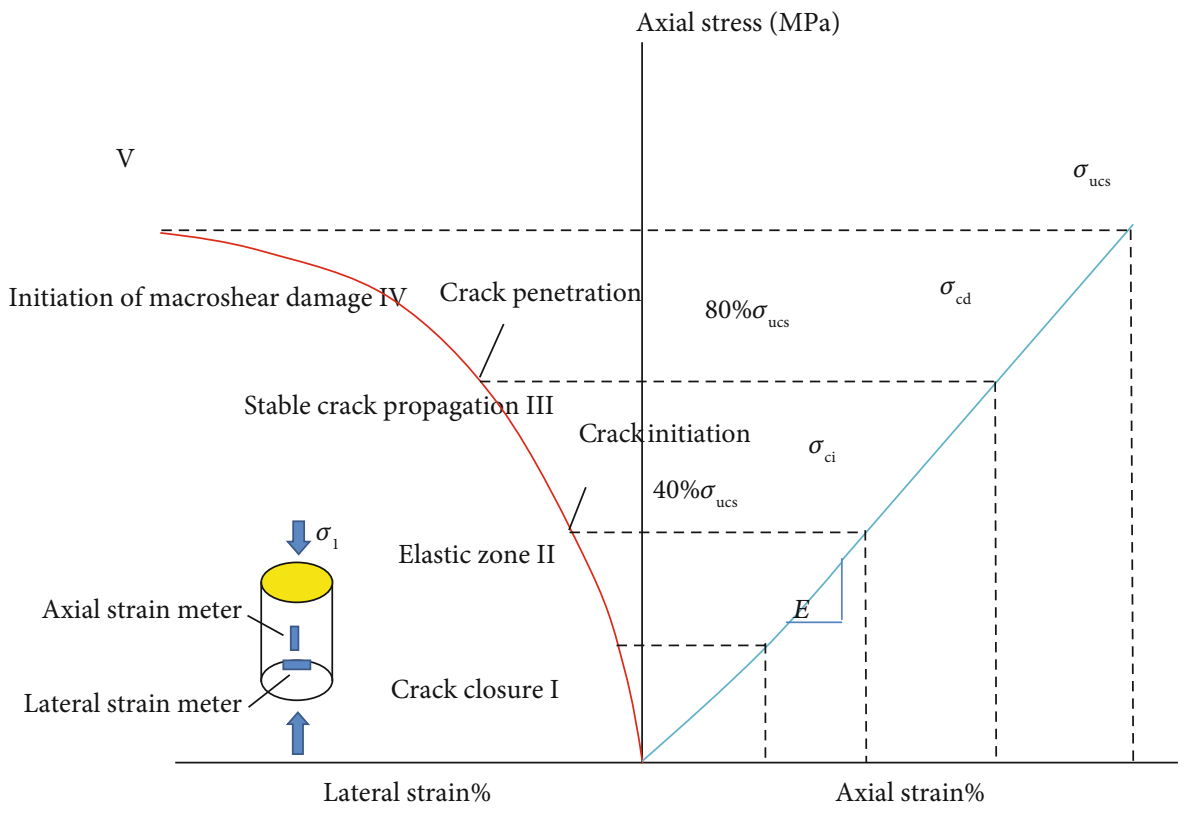

FIgURE 1: Typical stress-strain curves of rock under uniaxial compression.

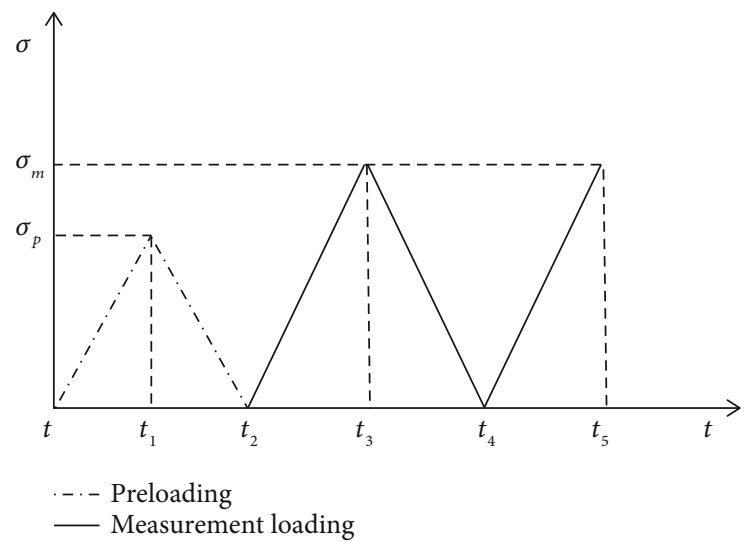

Figure 2: Loading regime.

memory information, namely, "measurement loading." The stress peak is labeled as $\sigma_{m}$. First of all, a strain differential function is defined as follows:

$$
\Delta \varepsilon_{i, j}(\sigma)=\varepsilon_{j}(\sigma)-\varepsilon_{i}(\sigma), \text { wherein } j>i,
$$

wherein $\varepsilon_{i}(\sigma)$ and $\varepsilon_{j}(\sigma)$ indicate axial strains in the $i^{\text {th }}$ and $j^{\text {th }}$ loading, respectively, and $\sigma$ is the corresponding axial stress. Positive values are taken for both strains and stresses in compression.

In Equation (1), reversible strain portions are eliminated from the axial strain curves generated by two successive compressions, providing a differential value $\Delta \varepsilon$ of the axial irreversible strain. As shown in Figure 3, a curve is drawn by taking the stress $\sigma$ versus the strain differential $\Delta \varepsilon$, which is the strain differential curve (also called the DRA curve). An obvious inflection point exists on the curve, with a corre- sponding stress $\sigma_{\mathrm{DRA}}$ being the memory information. This method is termed as the "DRA method."

The memory information precision ME refers to a ratio of $\sigma_{\text {DRA }}$ to $\sigma_{p}$ both formed after applying the preloading stress peak $\sigma_{p}$, given as

$$
\mathrm{ME}=\frac{\sigma_{\mathrm{DRA}}}{\sigma_{p}} \times 100 \% .
$$

The angle at DRA inflection $\theta$ refers to an angle at the inflection point on the DRA curve. As shown in Figure 3, the angle at DRA inflection may reflect the significance level of the DRA curve inflection point; the strain differential amplitude refers to the absolute difference value between the maximum and the minimum strain differentials on the DRA curve.

Conceptually, the rock DME effect is similar to the Kaiser effect to some extent. However, both effects differ significantly from each other in terms of mechanisms, theories, and physical test features. Therefore, the rock DME and Kaiser effects may not be confused together in a general way [30]. This paper focuses on the rock DME, and the discussion on Kaiser or other memory effects are not involved.

\section{Physical Tests}

3.1. Sample Preparation and Test Devices. We prepared a series of sandstone and granite by core drilling, cutting, polishing, and other processes into standard cuboid samples of $50 \times 50 \times 100 \mathrm{~mm}$ in size. As recommended by ISRM [31], the maximum nonparallelism between both ends of a rock sample should be controlled within $0.02 \mathrm{~mm}$, and both end surfaces should be flat and smooth. The completed samples are shown in Figure 4. The strain in the physical tests herein 


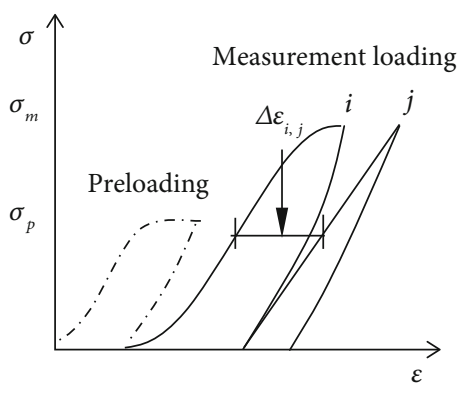

(a)

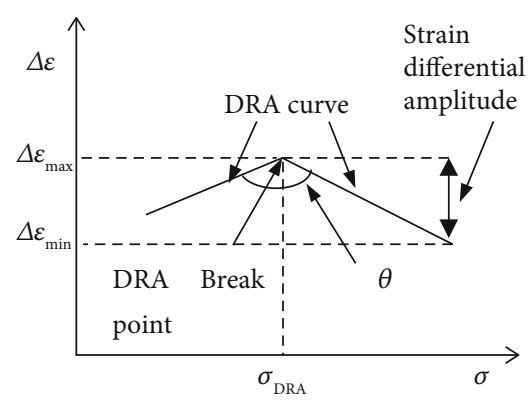

(b)

FIgure 3: Definition of deformation rate analysis. (a) Definition of strain differential $\Delta \varepsilon_{i, j}$; (b) DRA curve.

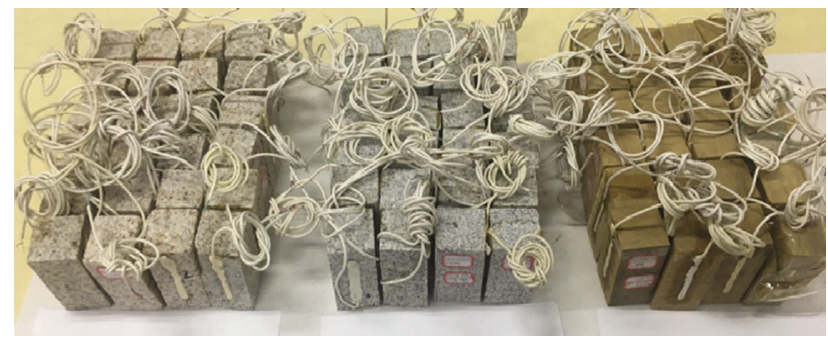

FIGURE 4: Granite and sandstone samples.
TABLE 1: Parameters of sandstone and granite samples in tests.

\begin{tabular}{lcccc}
\hline No. & Rock type & $\begin{array}{c}\text { Mean density } \\
\left(\mathrm{kg} / \mathrm{m}^{3}\right)\end{array}$ & $\begin{array}{c}\text { Mean UCS } \\
(\mathrm{MPa})\end{array}$ & $\begin{array}{c}\text { Mean elastic } \\
\text { modulus }(\mathrm{GPa})\end{array}$ \\
\hline $\begin{array}{l}\text { A1- } \\
\text { A36 }\end{array}$ & Granite A & 2654 & 105 & 65.6 \\
B1- & Granite B & 2736 & 193 & 73.2 \\
B36 & & & 56 & 52.8 \\
C1- & Sandstone & 2295 & 56 & \\
C36 & & & & \\
\hline
\end{tabular}

sion tests, and all the unit of strain difference is microstrain. It can be seen from Figure 7 that the DRA curves all significantly inflect downward near the precyclic loading, and all the stress read at DRA inflection is lower than that of precyclic loading.

3.3.2. Memory Information Precision. Figure 8 illustrates the variation of memory formation precision subject to variable precyclic loading times. Generally, as the precyclic loading times increase, the memory information precision of the sample grows gradually and becomes stable. As shown in Figure 7, subjected to 10 times of cyclic loading, the stresses at inflection in DRA curve for A, B, and C samples all turn into their precyclic loading stresses.

The memory information precision of the sample is sensitive to the cyclic loading times to varying degrees depending on rock types. As for granite A, granite B, and sandstone $\mathrm{C}$, the memory information precision formed under 10 times of cyclic loading grows by $6.3 \%, 7 \%$, and $10 \%$ in average compared to a single cycle, respectively. Meanwhile, as shown in Figure 8, as the cycle times increase, the discreteness of memory information precisions of different samples reduces.

3.3.3. Angle $\theta$ at DRA Inflection. Figure 9 illustrates the variation of the angle at DRA inflection subject to precyclic loading times. Three groups of different rock samples are in common with each other. In Figure 9, when the cyclic loading times increase, the DRA angle decreases gradually and then becomes stable. In other words, the DRA curve changes more sharply at the inflection point, and the inflection point becomes clearer and easier to identify. In Figures 7, 3 groups of typical DRA curves significantly show this feature. As the cycle times
3.3.1. DRA Curve Feature. Figure 7 illustrates typical DRA curves obtained by 1,5 , and 10 times of preloading with dif-

ferent rock samples and at stress levels in uniaxial compres-
3.2. Test Scheme. In order to investigate how the different precyclic loading times influence the rock DME, a cyclic Figure $6, \sigma_{p}$ is a cyclic loading amount, $\sigma_{m}$ is a measurement loading amount, and $m$ is the cyclic loading times. The detailed loading parameters and environmental parameters are listed in Table 2.

\subsection{Test Result and Analysis}




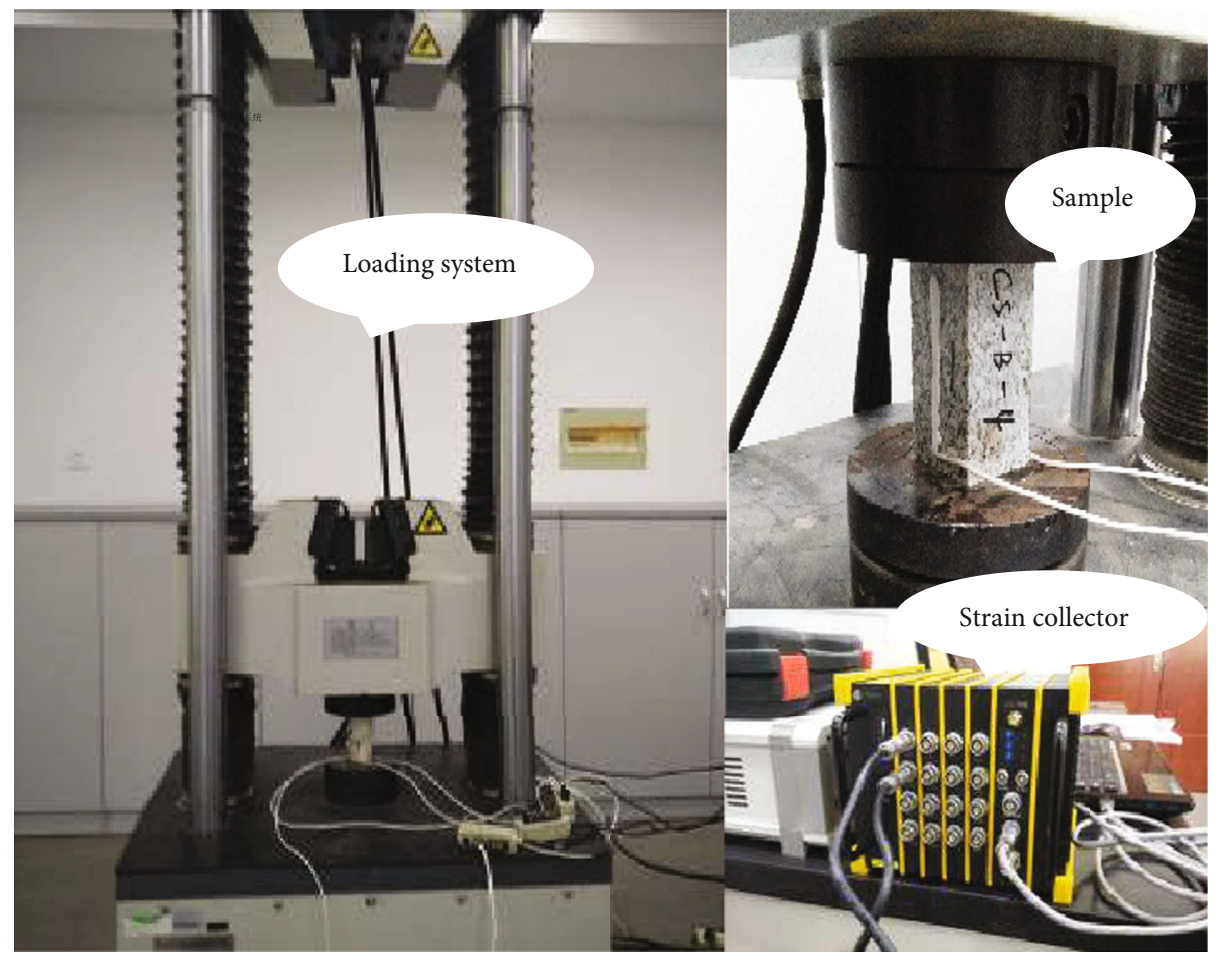

FIGURE 5: Loading system.

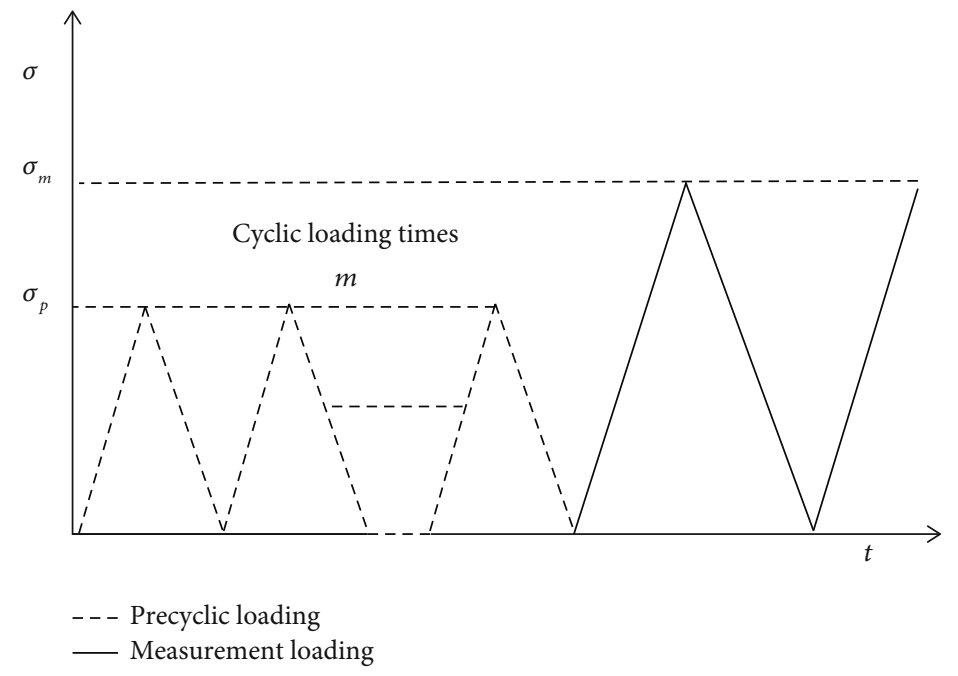

FIgure 6: Cyclic loading regime.

increase from 1 to 10 , an inflection angle decreases by $41^{\circ}$ in average for granite $\mathrm{A}, 36^{\circ}$ in average for granite $\mathrm{B}$, and $21^{\circ}$ in average for sandstone $\mathrm{C}$. However, due to similar memory information precisions, the inflection angles may not decrease without limitation. If the times reach a lower limit, the angle at DRA inflection also reaches its lower limit and shows no further change under the loading time variation.

3.3.4. Strain Differential Amplitude. Figure 10 illustrates the variation of the strain differential amplitude under the cyclic loading times; the unit of strain differential amplitudes is micro- strain. As the cyclic loading times increase, the strain differential amplitude of each sample DRA curve decreases gradually towards a stable value. That is, when the strain differential amplitude reaches a certain stable value, the cyclic loading times no longer influences the strain differential amplitude in the DRA curve. As for granite A, as the loading times grow from 1 to 10 , its mean strain differential amplitude drops by 58 microstrains. Correspondingly, 19 microstrains are cut down for granite B samples, and 90 microstrains are cut down for sandstone C. Meanwhile, as the cyclic loading times increase, the dispersion of the test result of each sample group is reduced. 
TABLE 2: Loading parameters and environmental parameters.

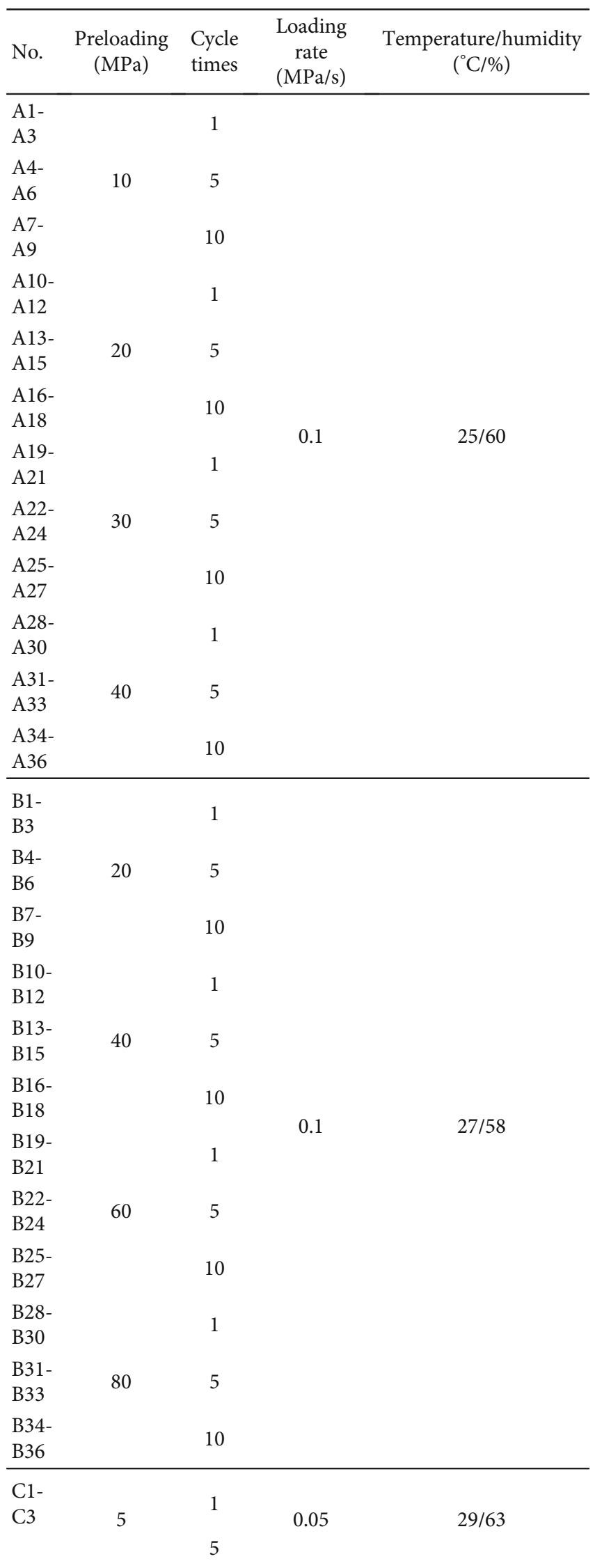

TABle 2: Continued.

\begin{tabular}{|c|c|c|c|c|}
\hline No. & $\begin{array}{l}\text { Preloading } \\
\quad(\mathrm{MPa})\end{array}$ & $\begin{array}{l}\text { Cycle } \\
\text { times }\end{array}$ & $\begin{array}{l}\text { Loading } \\
\text { rate } \\
(\mathrm{MPa} / \mathrm{s})\end{array}$ & $\begin{array}{l}\text { Temperature/humidity } \\
\left({ }^{\circ} \mathrm{C} / \%\right)\end{array}$ \\
\hline \multicolumn{5}{|l|}{$\begin{array}{l}\text { C4- } \\
\text { C6 }\end{array}$} \\
\hline $\begin{array}{l}\text { C7- } \\
\text { C9 }\end{array}$ & & 10 & & \\
\hline $\begin{array}{l}\mathrm{C} 10- \\
\mathrm{C} 12\end{array}$ & & 1 & & \\
\hline $\begin{array}{l}\text { C13- } \\
\text { C15 }\end{array}$ & 10 & 5 & & \\
\hline $\begin{array}{l}\text { C16- } \\
\text { C18 }\end{array}$ & & 10 & & \\
\hline $\begin{array}{l}\text { C19- } \\
\text { C21 }\end{array}$ & & 1 & & \\
\hline $\begin{array}{l}\text { C22- } \\
\text { C24 }\end{array}$ & 15 & 5 & & \\
\hline $\begin{array}{l}\mathrm{C} 25- \\
\mathrm{C} 27\end{array}$ & & 10 & & \\
\hline $\begin{array}{l}\text { C28- } \\
\text { C30 }\end{array}$ & & 1 & & \\
\hline $\begin{array}{l}\text { C31- } \\
\text { C33 }\end{array}$ & 20 & 5 & & \\
\hline $\begin{array}{l}\text { C34- } \\
\text { C36 }\end{array}$ & & 10 & & \\
\hline
\end{tabular}

\section{Theoretical Model}

4.1. Fiction Sliding on Microstructure Surface. Rock is a material containing a large quantity of randomly distributed microstructure surfaces [32]. Taking the unit volume into consideration, the uniform strain status $[33,34]$ of the material containing multiple microstructure surfaces under a uniform stress is given as

$$
\left\{\begin{array}{l}
\sigma_{i k}=\sigma_{i k}^{0}, \\
\varepsilon_{i k}=\varepsilon_{i k}^{0}+\frac{1}{2} \sum_{\alpha}\left(n_{i} V_{k}^{\alpha}+n_{k} V_{i}^{\alpha}\right),
\end{array}\right.
$$

wherein $\sigma_{i k}$ is the stress tension in a unit volume, $\varepsilon_{i k}{ }^{0}$ and $\sigma_{i k}{ }^{0}$ are elastic matrix strain and stress tension, not influenced by the microstructure surface, $n_{i}$ is the exterior normal unit vector of the microstructure surface, and $V_{i}$ is the volume of the microstructure surface. The strain of the material containing microstructure surfaces consists of two parts, one of which is generated from the elastic matrix and the other is generated from microstructure surfaces. Plenty of factors may influence the second part's mechanic behaviors, such as the orientations and dimensions, as well as media properties between the microstructure surfaces.

As indicated in Introduction, models based on crack propagation may not explain the generation of rock deformation memory effect within low-stress zones. Therefore, the generation of rock deformation memory effect is to be 

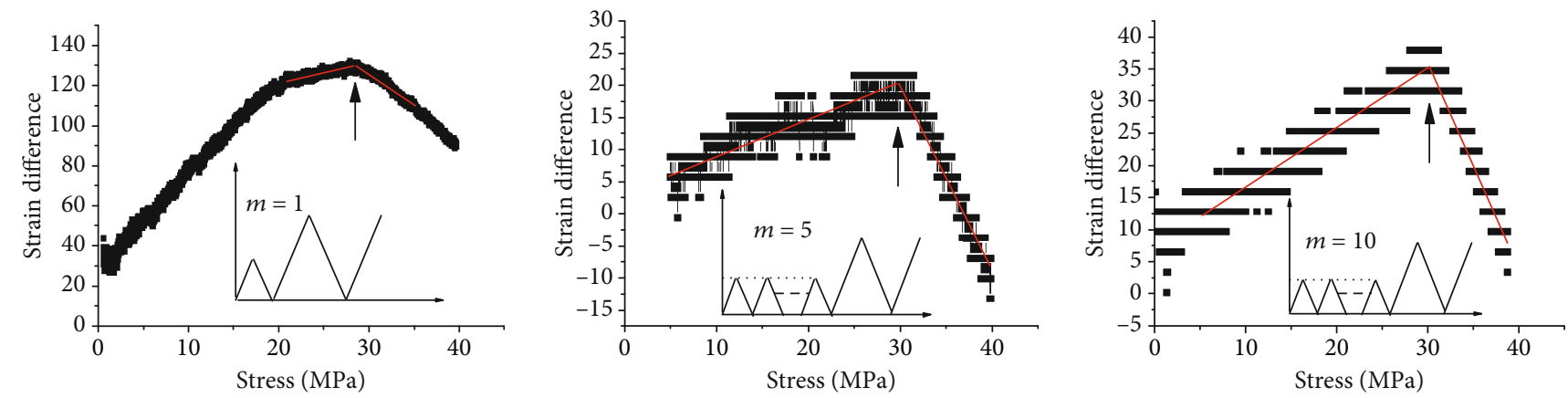

(a) Granite A with a stress peak of $30 \mathrm{MPa}$, measurement loading at $40 \mathrm{MPa}$
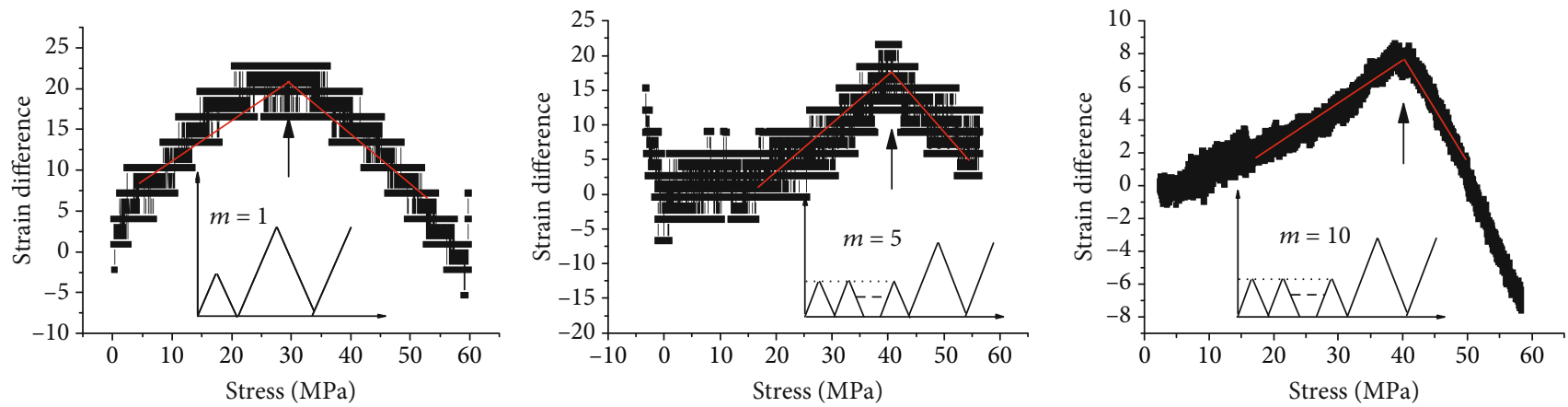

(b) Granite B with a stress peak of $40 \mathrm{MPa}$, measurement loading at $60 \mathrm{MPa}$
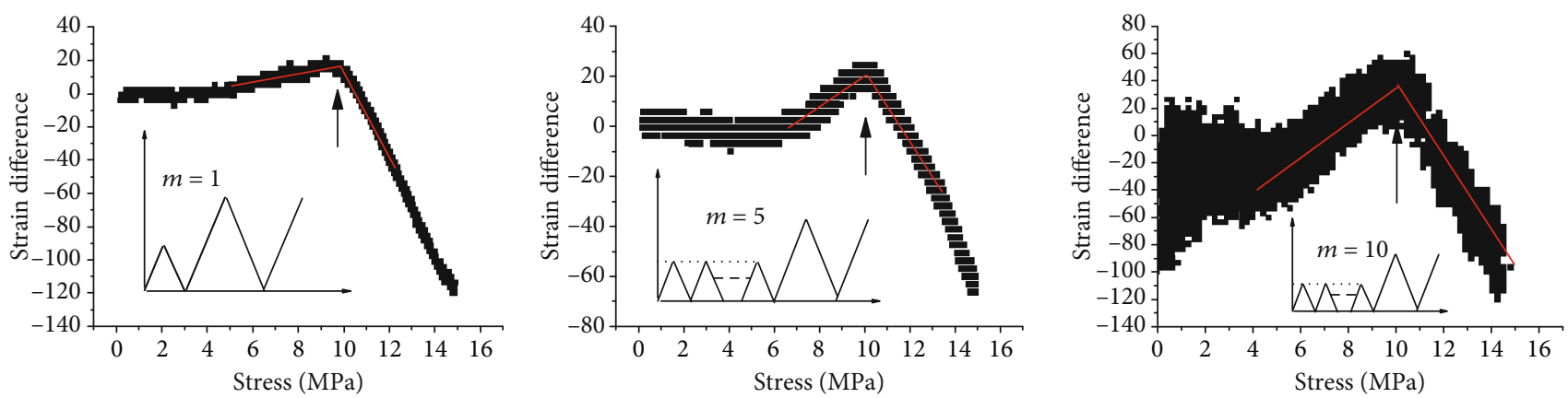

(c) Sandstone $\mathrm{C}$ with a stress peak of $10 \mathrm{MPa}$, measurement loading at $15 \mathrm{MPa}$

FIgURe 7: Typical DRA curves by different rocks and stress levels.

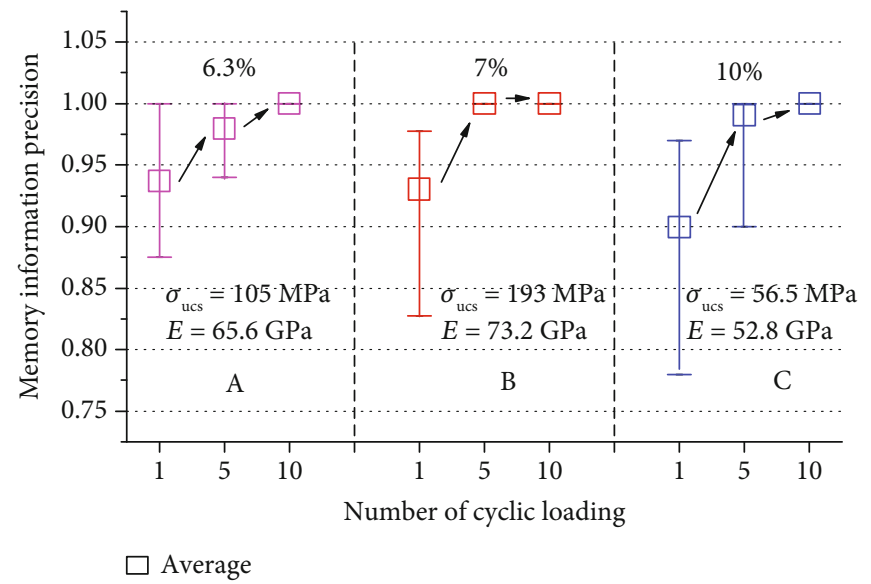

Figure 8: Variation of memory precision under different cyclic load times. 


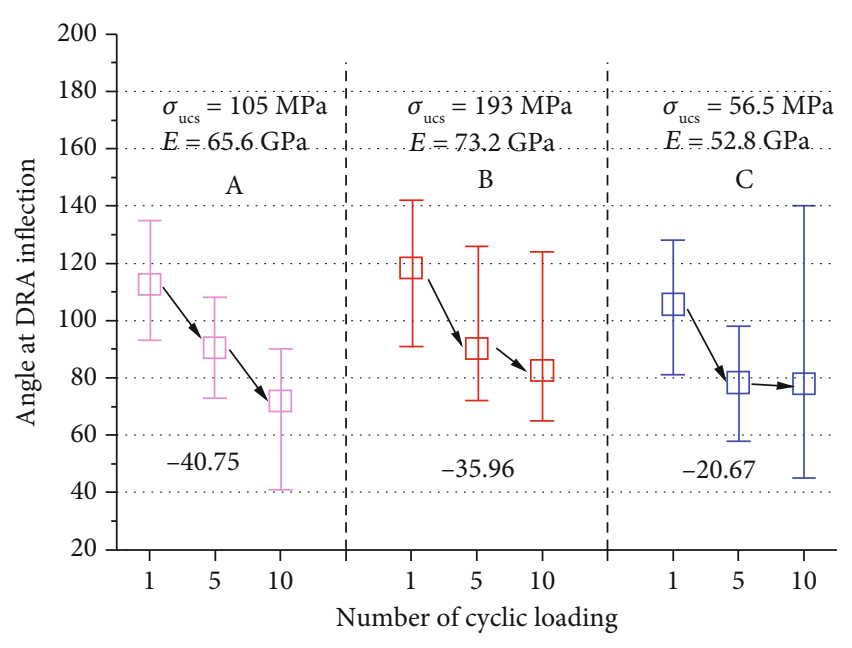

$\square$ Average

FIGURE 9: Variation of the angle at DRA inflection under different cyclic load times.

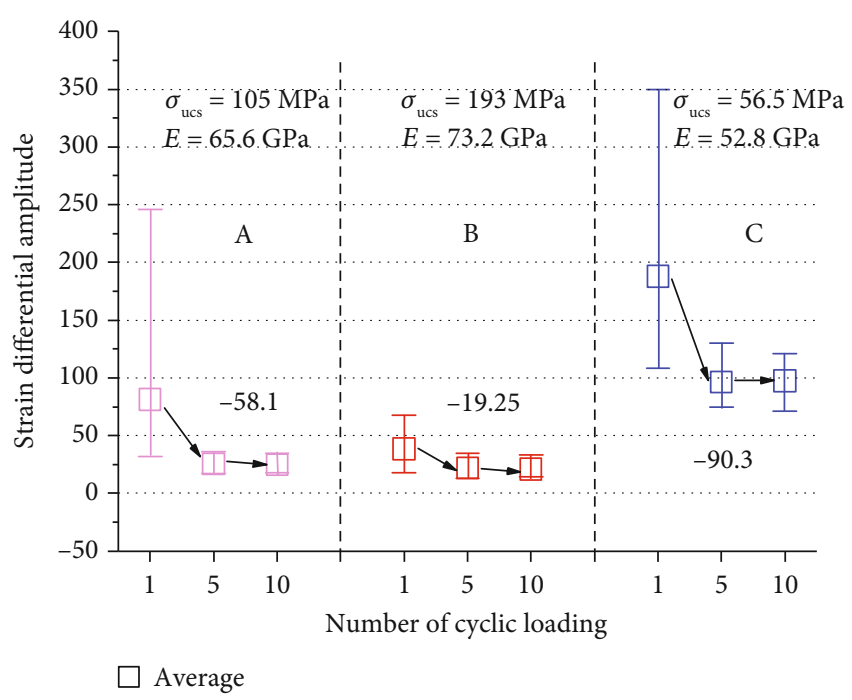

Figure 10: Variation of strain difference amplitude under different cyclic load times.

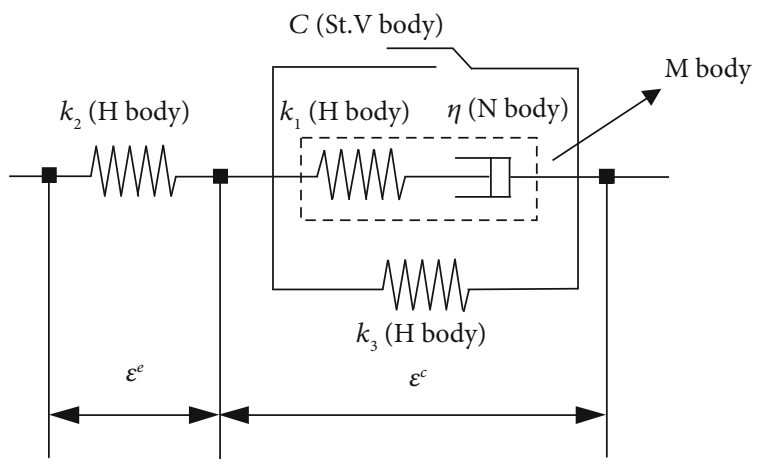

Figure 11: Basic memory element. attributed to friction sliding on microstructure surfaces. Accordingly, a basic memory element of the unit-volume rock containing a single microstructure surface is modeled by combining the elastic component ( $\mathrm{H}$ body), viscous component ( $\mathrm{N}$ body), and the Saint-Venant body (St.V body), thus enabling the simulation of friction sliding on the microstructure surfaces.

4.2. Friction Sliding Model of Multiple Microstructure Surfaces. As shown in Figure 11, a basic memory element consists of two parts, one of which is an $\mathrm{H}$ body $k_{2}$ used for characterizing the elastic matrix surrounding the microstructure surface, while the other part is formed by an $\mathrm{H}$ body $k_{3}$, a Maxwell body, and a St.V body connected in parallel. The Maxwell body is formed by an $\mathrm{H}$ body and an $\mathrm{N}$ body connected in series and called $\mathrm{M}$ body for short. The $\mathrm{M}$ body represents the contribution of the microcrack and particle contact surface mechanic behaviors to the rock deformation, which is expressed with "Spr||Maxwell||St.V," where "I|" indicates connection in parallel and "Spr" indicates the elastic component.

The $\mathrm{H}$ body constitutive equation is consistent with Hooke's law. As for the St.V body, when the stress applied on a component reaches a cohesion limit, the stress keeps unchanged while the strain keeps growing. The stress limit in the basic element is the cohesion $c$. As for the $\mathrm{N}$ body, the stress is in direct proportion to strain. The Maxwell body is formed by an $\mathrm{H}$ body and an $\mathrm{N}$ body connected in series, which is called $\mathrm{M}$ body for short. The $\mathrm{H}$ body is connected in series with the $\mathrm{N}$ body, both of which are subject to the same stress. The strain of the $\mathrm{M}$ body is the sum of the $\mathrm{H}$ body and $\mathrm{N}$ body strains. Constitutive equations of all basic element bodies are given as Equations (4)-(9) as follows:

$$
\text { Hbody : } \sigma=k \varepsilon \text {, }
$$

$$
\text { St.V body : } \begin{cases}\varepsilon=0 & \left(\sigma<\sigma_{s}\right), \\ \varepsilon \rightarrow \infty & \left(\sigma \geq \sigma_{s}\right),\end{cases}
$$

$$
\mathrm{N} \text { body }: \sigma(t)=\eta \frac{d \varepsilon(t)}{d t}
$$

$$
\text { M body : } \frac{d \varepsilon(t)}{d t}=\frac{1}{k} \frac{d \sigma(t)}{d t}+\frac{\sigma(t)}{\eta} \text {, }
$$

wherein $k$ is an elasticity modulus, $\sigma_{s}$ is a stress limit, $\eta$ is a viscous parameter, and $t$ is time.

The theoretical model of basic memory elements is formed by combining the above basic components, with mechanic behaviors of each component remaining consistent with Equations (4)-(7). As the left elastic component is connected with the "Spr||Maxwell||St.V" body in series, if setting the applied stress to $\sigma$, the component and the body are subject to the same stress, and the strain equals to a sum of strain on both components as

$$
\left\{\begin{array}{l}
\sigma=\sigma^{e}=\sigma^{c} \\
\varepsilon=\varepsilon^{e}+\varepsilon^{c}
\end{array}\right.
$$


wherein $\sigma^{e}$ and $\varepsilon^{e}$ represent, the stress and strain of the elastic matrix, respectively; $\sigma^{c}$ and $\varepsilon^{c}$ represent the stress and strain of the "Spr||Maxwell||St.V" body, respectively. As for the "Spr||Maxwell||St.V" body, three components are connected with each other in parallel, and the stress $\sigma^{c}$ of the body equals to a sum of stresses on the three components as

$$
\sigma^{c}=\sigma_{\text {fric }}+\sigma_{\text {sprl }}+\sigma_{\text {spr } 3},
$$

wherein $\sigma_{\text {fric }}$ represents the stress of the St.V body, $\sigma_{\text {sprl }}$ represents the stress of the $\mathrm{H}$ body $k_{1}$, and $\sigma_{\text {spr3 }}$ represents the stress of the $\mathrm{H}$ body $k_{3}$.

The Maxwell body is formed by the $\mathrm{H}$ body $k_{1}$ and the $\mathrm{N}$ body connected in series, both of which are subject to the same stress, and the body strain equals to a sum of strain on the two components:

$$
\left\{\begin{array}{l}
\varepsilon^{c}=\varepsilon_{\mathrm{das}}+\varepsilon_{\mathrm{spr} 1}, \\
\sigma_{\mathrm{das}}=\sigma_{\mathrm{spr} 1},
\end{array}\right.
$$

wherein $\sigma_{\text {das }}$ and $\varepsilon_{\text {das }}$ are the stress and strain of the $\mathrm{N}$ body, respectively, and $\varepsilon_{\text {sprl }}$ represents the strain of the $\mathrm{H}$ body $k_{1}$, which satisfies

$$
\left\{\begin{array}{l}
\sigma_{\mathrm{spr} 1}=k_{1} \varepsilon_{\mathrm{spr} 1}, \\
\sigma_{\mathrm{das}}=\frac{\eta \partial \varepsilon_{\mathrm{das}}}{\partial t} .
\end{array}\right.
$$

The St.V body has two conditions, stationary and sliding, which should be determined upon a comparison of its stress to its cohesion. When the stress surpasses the cohesion, the "Spr||Maxwell||St.V" body starts sliding, and the stress of St.V body remains unchanged, which always equals to the cohesion. When the stress is less than the cohesion, the St.V body stops sliding and stays stationary, and the entire "Spr||Maxwell||St.V" body is "locked" by the St.V body, which is

$$
\begin{gathered}
\text { Sliding condition : }\left|\sigma_{\text {fric }}\right|=c, \\
\text { Stationary condition : }\left\{\begin{array}{l}
\left|\sigma_{\text {fric }}\right|<c, \\
\varepsilon^{c}=\varepsilon_{0}^{c},
\end{array}\right.
\end{gathered}
$$

wherein $\varepsilon_{0}^{c}$ is the initial strain of the "Spr||Maxwell||St.V" body. At this point, the $\mathrm{H}$ body $k_{1}$ and the $\mathrm{H}$ body $k_{3}$ cannot recover from deformation, allowing for storing the elastic potential energy. As the time elapses, the $\mathrm{H}$ body $k_{1}$ will drain its elastic potential energy through the viscous component, which satisfies

$$
\sigma=k \varepsilon_{0}^{c} e^{-k t / \eta} .
$$

Therefore, the differential equation of a basic element model can be given as

$$
\left\{\begin{array}{l}
\sigma=\sigma_{\text {fric }}+\frac{\eta^{d \varepsilon} \text { das }}{d t}+k_{3} \varepsilon_{1}, \\
\varepsilon^{c}=\frac{\eta^{d \varepsilon} \text { das }}{k_{1} d t}+\varepsilon_{\text {das }} .
\end{array}\right.
$$

The most basic loading scheme, as shown in Figure 2, may be obtained as

$$
\begin{aligned}
\varepsilon_{\text {das }}= & -A\left(\frac{c-r t+C}{k_{3}}+\frac{\eta\left(k_{1}+k_{3}\right) r}{k_{1} k_{3}^{2}}\right. \\
& -\frac{k_{3} e^{k_{1} k_{3} /\left(\eta\left(k_{1}+k_{3}\right)\right)}\left(\left((c-B r+C) / k_{3}\right)+\left(\left(\eta\left(k_{1}+k_{3}\right) r\right) / k_{1} k_{3}^{2}\right)\right)}{\left.k_{3}^{2} e^{k_{1} k_{3} t /\left(\eta\left(k 1+k_{3}\right)\right)}\right),} \\
\frac{d \varepsilon_{\text {das }}}{d t}= & -A\left(\frac{r}{k_{3}}-\frac{k_{1} k_{3} e^{B k_{1} k_{3} /\left(\eta\left(k_{1}+k_{3}\right)\right)}\left(\left((c-B r) / k_{3}\right)+\left(\left(\eta\left(k_{1}+k_{3}\right) r\right) / k_{1} k_{3}^{2}\right)\right)}{\eta\left(k 1+k_{3}\right) e^{k_{1} k_{3} t /\left(\eta\left(k 1+k_{3}\right)\right)}}\right),
\end{aligned}
$$

wherein

$$
\left\{\begin{array}{l}
t=t_{1}: A=1, C=0, \\
t=t_{2}: A=-1, C=r\left(t_{1}-t_{0}\right), \\
t=t_{3}: A=1, C=0, \\
t=t_{4}: A=-1, C=r\left(t_{4}-t_{3}\right), \\
t=t_{5}: A=1, C=0 .
\end{array}\right.
$$

$B$ is the time point during each loading when a St.V body reaches a threshold $c$, and $r$ is the loading rate.

The rock sample contains a large quantity of randomly distributed microstructure surfaces. Based on basic elements herein, a theoretical model is built for multiple contact surfaces containing $n$ basic elements, each of which is connected with another in series so as to simulate the rock sample (without counting in mutual influences between contact surfaces of the rock interior):

$$
\left\{\begin{array}{l}
\sigma=\sigma^{a}, \\
\varepsilon=\sum_{a=1}^{n} \varepsilon^{a},
\end{array}\right.
$$

wherein $n$ is a serial number of the contact surface, $\sigma$ is a total stress of the theoretical model, $\sigma^{\alpha}$ is a stress of the contact surface $\alpha, \varepsilon$ is a total strain of the theoretical model, and $\varepsilon^{\alpha}$ is a strain of the contact surface.

In combination with external loading conditions, the stress-strain relation of an axial symmetrical model of multiple contact surfaces may be calculated by Equations (14)-(17). In turn, the DRA curves may be obtained.

4.3. Calculation Parameters of the Theoretical Model. The loading scheme applied in the theoretical model calculation herein is consistent with that in the physical test, as shown in Figure 5.

200 basic elements in series are selected to do the theoretical model calculation $(n=200)$. For each of the basic 

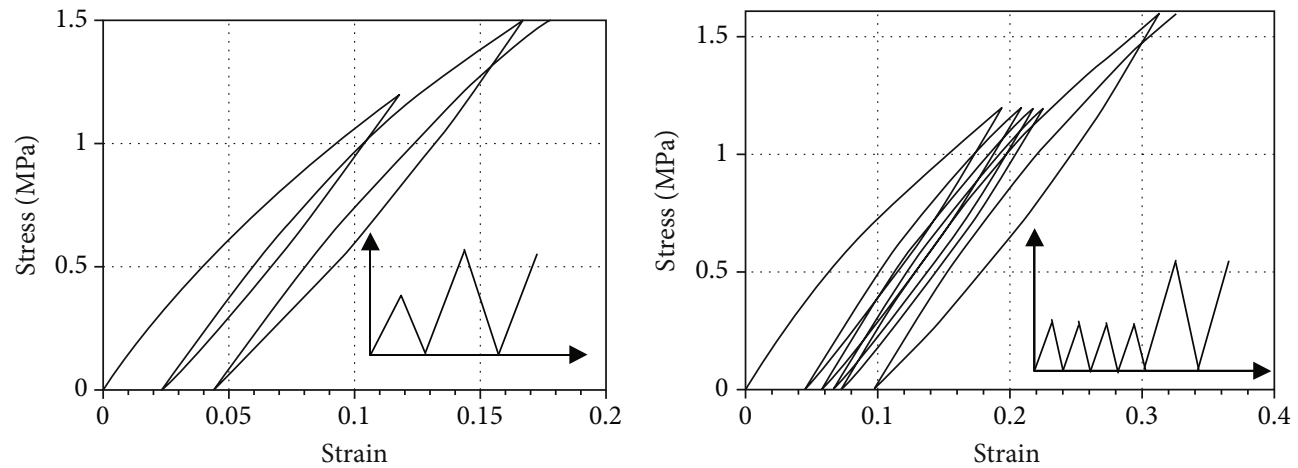

FIgURE 12: Typical stress-strain curves of the theoretical model.

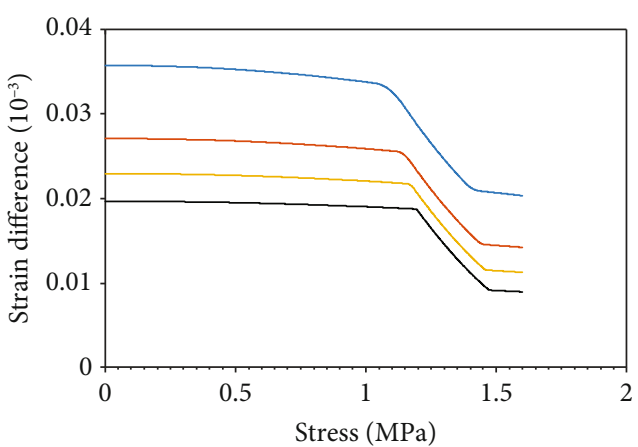

Cyclic times

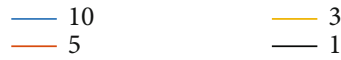

FIgURE 13: Typical DRA curves of the theoretical model under different cyclic times.

elements, the cohesion $c$ is arranged and distributed uniformly at 0-2 MPa, while the rest of basic mechanic parameters are all the same: $k_{1}=1 \times 10^{2} \mathrm{MPa}, k_{2}=5 \times 10^{2} \mathrm{MPa}$, $k_{3}=1 \times 10^{2} \mathrm{MPa}, \mu=0.25$, and $\eta=1 \times 10^{14}$. The cyclic loading time $m$ is set as 1 to 10 , respectively. To do a more efficient calculation, $\sigma_{p}=1.2 \mathrm{MPa}$ and $\sigma_{m}=1.5 \mathrm{MPa}$ are set.

\subsection{Comparison between Results from Theoretical Model Calculation and Physical Tests}

4.4.1. Basic Features of DRA Curves in the Theoretical Model. Figure 12 illustrates typical stress-strain curves of a theoretical calculation model performing 1 and 4 times of cyclic loading, respectively. As for typical DRA curves of the theoretical model, 1, 3, 5, and 10 are taken as the cyclic loading times, as shown in Figure 13. A sliding friction model of multimicrostructure surfaces may form a DRA curve inflecting downward, and stress values corresponding to points at DRA inflection are all less than preloading peak value $\sigma_{p}$, which means this model may simulate the deformation memory effect. As can be seen from Figure 13, as the cyclic loading times increase, the DRA curve inflection points gradually shift to the preloading peak point, i.e., the memory information precisions are gradually improved. The angles at DRA inflection decrease slightly, but the curvatures at the inflec- tion points decrease gradually. The strain differential amplitudes also decrease gradually.

\subsubsection{Comparison of Memory Information Precision.}

Figure 14 illustrates comparative curves of the memory information precision. As the cyclic loading times increase, the memory information precision grows fast initially and then slows down, finally reaching $100 \%$ which equals to the exact memory preloading value. As shown in Figure 14, the memory information precision increases by $8.45 \%$ at most in the entire course. The variation of the theoretical model is consistent with those of physical test results for the three rock samples, except a certain deviation when the cyclic loading is performed for around 5 times.

4.4.3. Comparison of Angles at DRA Inflection. Figure 15 illustrates comparative curves of angles at DRA inflection. As the cyclic loading times increase, the smooth curve at DRA inflection points turns into sharp points. The DRA curve changes from an oblique and smooth curve into a horizontal straight line prior to the inflection point. The angles at DRA inflection become smaller gradually, decreasing by 14 degrees at most. However, the angles at DRA inflection are going towards a stable value, and the DRA curve tends to be stable without any change when increasing the cyclic loading times. The physical test result is consistent with the theoretical model in terms of variation.

4.4.4. Comparison of Strain Differential Amplitudes. Figure 16 illustrates comparative curves of strain differential amplitudes; the unit of theoretical strain differential amplitudes is millistrain, and the unit of experimental is microstrain. As the cyclic loading times increase, the strain differential amplitudes decrease gradually. In addition, the strain differential amplitudes change sharply at the early stage of the cyclic loading time increase. Then, they slow down later until saturation at last, which means that the increase of cyclic loading times causes almost no change to the strain differential amplitudes. During the increase of cyclic loading times, the strain differential amplitudes decrease by 0.0875 millistrain at most which accounts for approximately $13 \%$ of the initial strain differential amplitude. Because the theoretical model adopts a loading peak value different from that of the physical test, focus is only put on 


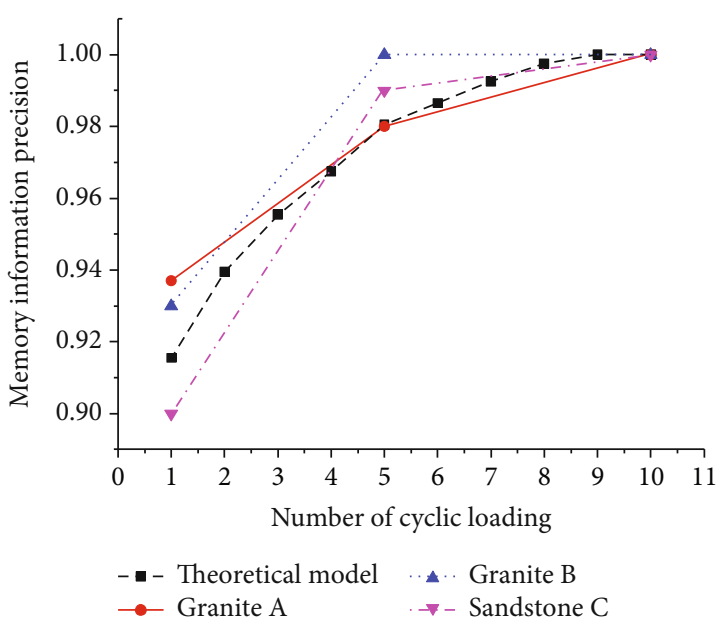

Figure 14: Comparison of memory precision between the theoretical model and the experiment.

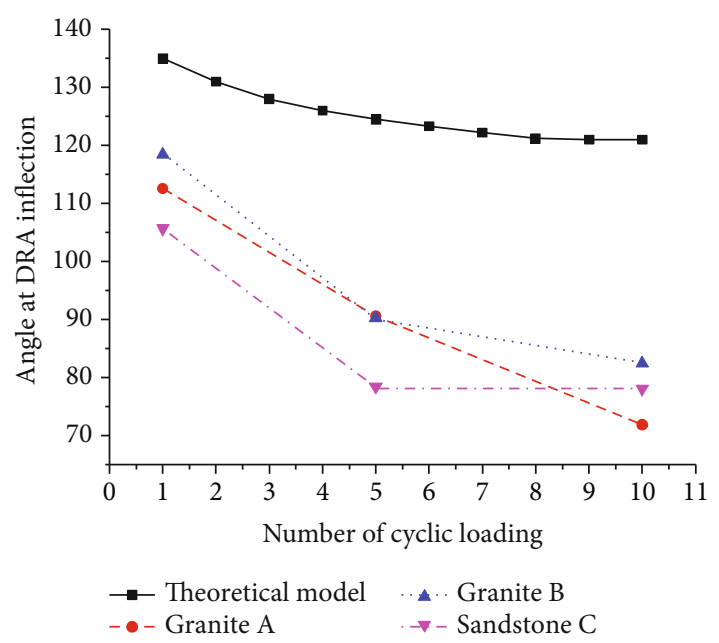

Figure 15: Comparison of DRA angle between the theoretical model and the experiment.

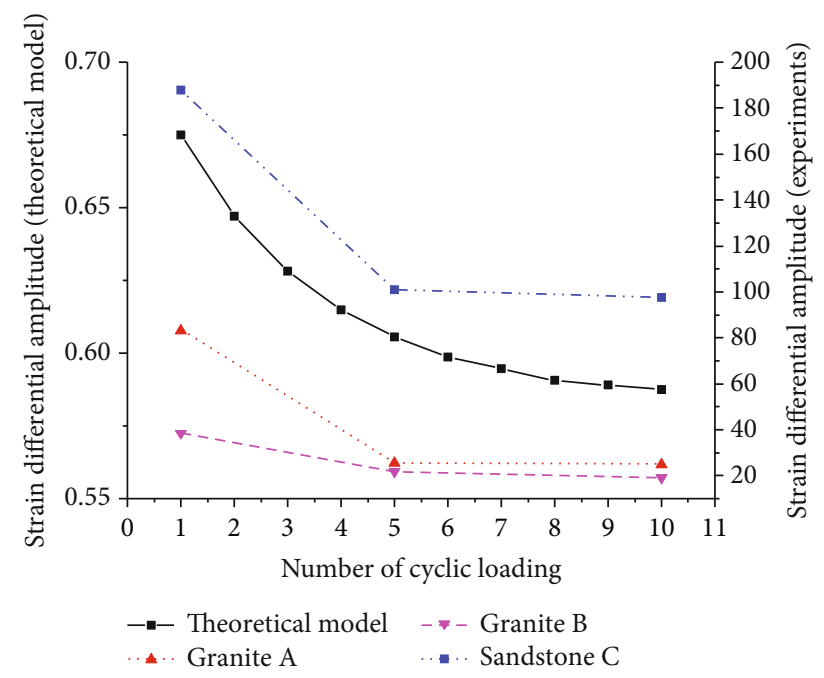

Figure 16: Comparison of stain difference amplitude between the theoretical model and the experiment. the variation of the strain differential amplitudes, in terms of which the theoretical model is consistent with the physical.

\section{Discussions}

5.1. DME Features and Memory Information Precision. All DRA curves herein inflect downward at or prior to the formation of memory information, which is consistent with that concluded by most researchers, e.g., Seto et al. [9] and $\mathrm{Wu}$ et al. [35], proving the correctness of the basic test. However, some researchers, such as Park et al. [10], obtained opposite test results: the DRA curve inflection points generally surpass the memory information. This is mainly because they fitted strain data by MATLAB, which influenced the points at DRA inflection.

In terms of the memory formation precision, it is concluded that under a certain condition, the more times of cyclic loading are performed, the larger the memory formation precision will be. It may be seen from the theoretical model that rock is a viscoelastic plastic medium of which the microstructure, once the peak stress is unloaded, changes to a certain degree of reversibility. For example, the remaining strain is not the one under the peak, and its increment will change along with the loading and unloading processes. When the cyclic loading times increase, the remaining strain increment is gradually reduced to 0 which means no change to the remaining strain. At this point, the rock interior microstructure loses its reversibility utterly, and the rock information precision reaches $100 \%$. Therefore, when the precycle times increase to a certain degree, the memory formation precision may stop growing. That is, no stress peak at the DRA curve inflection point will surpass the memory information. The theoretical model is consistent with the physical test in terms of the conclusion.

5.2. Determination of the Best Cycle Times. As mentioned above, when conducting DME research, researchers did not simply use a single loading method to form memory. Most of them used the cyclic loading methods, so it became a problem how to determine the best cycle times.

Both the physical experiment and the theoretical model in this paper show that with the increasing cyclic loading times, the amplitude of the strain difference gradually decreases to unchanged, while the memory information precision is stable at the same time.

A new way of determining the best cycle times is proposed here. That is, a precycle, performed such that the strain differential amplitude on the DRA curve stops changing, has reached its best cycle times. Some researchers [14] in existing studies have proposed a concept of "saturated strain" and taken it as the way of determining the best cycle times. It means if a strain stops changing, or changes within a certain error range, when the cycle times increase to a certain extent, it is believed that the strain has reached saturation and the cycle times at this point are the best. This method may be used to determine the best cycle times if the strain measurement is completely accurate. Unfortunately, it is impossible to make each strain measurement perfectly accurate during the experiment as strain gauges often float away. In 
particular, in the case of analyzing hard rock with inherently small strain, the strain changes sharply once unloaded completely, making the rock strain prone to be overridden. Therefore, when the strain gauges float such that the strain measurement error surpasses the error allowable to the saturated strain, this method is not able to determine if the cycle times at a point are the best or not. However, the strain differential amplitude may bypass occasional errors caused by the strain. DRA curves are drawn by differences between strains out of two tests, and the difference between the maximum and the minimum strain differentials is taken as the determination standard. When the difference stops changing, or changes within a given error range, the cyclic loading times at this point are the best. The strain differential amplitude may be read directly from the DRA curve, making it a more convenient and rapid way than the "saturated strain" method. As to this conclusion, the physical test is consistent with the theoretical model.

5.3. Theoretical Modelling. As indicated in Introduction, some researchers adopted "picking or promoting commercial software $\rightarrow$ parameter adjustment $\rightarrow$ fitting test data $\rightarrow$ believing that the commercial built-in model is the mechanical mechanism" idea with their studies on the DME mechanisms and theories. However, on the one hand, the commercial software itself brings many inherent assumptions and simplification, and on the other hand, the built-in model of the commercial software is not oriented to DME. It still needs discussion whether the model could be considered as a true DME mechanism and used in result forecasting even if a perfect fitting effect is achieved through parameter adjustment. For example, Seto et al. [23] succeed in fitting part of test data by adjusting PFC2D parameters, but "no DME exists in zones of stresses lower than the initial micro crack stress value" they concluded utterly contradicts the physical test result.

Therefore, in terms of theory study, the author did not intentionally fit test data, but "identified which fundamental physics and material microstructure mechanics would be the potential mechanism in the first place $\rightarrow$ described this physical mechanism by introducing math models and reasonably combining the model of three basic rock element$s \rightarrow$ obtained the rock DME mechanics features in the macro sense and compared with the test $\rightarrow$ thereby disclosed the operating mechanism from mechanism to phenomenon." The theoretical model built herein shares the same variation rule with the physical test, which supports the rationality and applicability of the theoretical model.

5.4. Positive Effect in In Situ Stress Measurement. As the experimental and theoretical results show, the memory information precision of rock increases and is closed to $100 \%$ with the preloading times increasing. It means the memory information of rock would not be lost nearly under cyclic loading which means without other factors disturbing, the stress measured by the DRA method would be the real in situ stress if we can judge the rock was under cyclic loading before through the geological survey.

\section{Conclusions}

Through the DRA test of granite and sandstone, the basic laws of rock DME under cyclic loading with different stress levels are obtained. The memory theory model is established based on the friction and sliding mechanism of the microstructure surface, which is used to carry out the analysis of rock DME under cyclic loading; compared with the test results, the main conclusions are as follows:

(1) The DRA tests and theoretical analysis show that as the number of cyclic loading times increases, the rock DME memory information precision significantly improves and then almost reaches accuracy; the angle at DRA inflection becomes sharper which indicates that the point at DRA inflection becomes more explicit and interpretable; strain differential amplitude in the DRA curve gradually decreases and then tends to be a stable value

(2) As for the memory model built on the basis of the friction sliding hysteresis and the energy transferring mechanism, the features of how the cyclic loading influences the rock DME can be described through the mechanic nonlinear behaviors of rock microstructure surfaces

(3) An upper limit exists for influence, meaning the best cyclic loading times occur when the pulse amplitude of the strain differential stops changing. Its appearance provides a better outcome for experiment using artificial preload when DME is utilized for stress reconstruction

(4) Without other factors disturbing, the memory information of the in situ stress would hardly lose under the history of cyclic loading

\section{Data Availability}

The experimental and theoretical data used to support the findings of this study are available from the corresponding author upon request.

\section{Conflicts of Interest}

The authors declare that there is no conflict of interest regarding the publication of this paper.

\section{Acknowledgments}

This research was financially supported by the National Natural Science Foundation of China (Grant Nos. U1765204 and 51409170), the Fundamental Research Funds for the Central Universities (Grant No. 2019B71914), the Natural Science Foundation of Jiangsu Province (Grant No. BK20171130), the China Scholarship Council (Grant/Award Number: 201906710161), and the Postgraduate Research \& Practice Innovation Program of Jiangsu Province (Grant No. SJKY19_0490). 


\section{References}

[1] V. S. Yamshchikov, V. L. Shkuratnik, and A. V. Lavrov, "Memory effects in rocks (review)," Journal of Mining Science, vol. 30, no. 5, pp. 463-473, 1994.

[2] K. Yamamoto, Y. Kuwahara, N. Kato, and T. Hirasawa, "Deformation rate analysis: a new method for in situ stress estimation from inelastic deformation of rock samples under uni-axial compression," Science Reports of the Tohoku University Fifth, vol. 33, no. 2, p. 34, 1990.

[3] V. L. Shkuratnik and A. V. Lavrov, "A theoretical model of the electromagnetic emission effect of rock memory," Journal of Applied Mechanics and Technical Physics, vol. 37, no. 6, pp. 913-916, 1996.

[4] S. P. Hunt, A. G. Meyers, and V. Louchnikov, "Modelling the Kaiser effect and deformation rate analysis in sandstone using the discrete element method," Computers and Geotechnics, vol. 30, no. 7, pp. 611-621, 2003.

[5] M. Utagawa, M. Seto, and K. Katsuyama, "Estimation of initial stress by deformation rate analysis (DRA)," International Journal of Rock Mechanics and Mining Sciences, vol. 34, no. 3-4, pp. 317.e1-317.e13, 1997.

[6] D. K. Liu, Z. L. Gu, R. X. Liang et al., "Impacts of pore-throat system on fractal characterization of tight sandstones," Geofluids, vol. 2020, Article ID 4941501, 17 pages, 2020.

[7] J. Wang, Y. Zhang, Z. Qin, S. G. Song, and P. Lin, “Analysis method of water inrush for tunnels with damaged waterresisting rock mass based on finite element method-smooth particle hydrodynamics coupling," Computers and Geotechnics, vol. 126, p. 103725, 2020.

[8] T. GOTO, J. KODAMA, K. ITAKURA, and Y. YOSHIDA, "Application of the ultrasonic propagation time of a core sample for stress measurement of underground rocks," Shigen-toSozai, vol. 113, no. 8, pp. 593-599, 1997.

[9] M. V. E. Seto, In situ stress determination by acoustic emission techniques from McArthur River mine cores, National Institute for Resources and Environment, 1999.

[10] P. Park, N. Park, C. Hong, S. Jeon, and Y. Kim, The influence of delay time and confining pressure on in-situ stress measurement using $A E$ and DRA, American Rock Mechanics Association, 2001.

[11] H. Shimada, F. Goto, M. Seto, and K. Matsui, "Fundamental study on applicability on in-situ stress using DRA methodeffect of confining pressure and stress level on estimation of previous stress," Shigen-to-Sozai, vol. 117, no. 3, pp. 202-208, 2001, (in Japanese).

[12] N. Soma, M. Seto, H. Matsui, and N. Maeda, "Stress determination from rock cores using the acoustic emission method under confining pressure," Shigen-to-Sozai, vol. 118, no. 8, pp. 546-552, 2002, (in Japanese).

[13] I. Attar, M. Ahmadi, M. Nikkhah, and A. Attar, "Investigating the capability of deformation rate analysis method in stress estimation: a case study of water conveyance tunnel of Gotvand Dam," Arabian Journal of Geosciences, vol. 7, no. 4, pp. 1479-1489, 2014.

[14] J. Zhang, Investigating the Laboratory Experiments to Estimate Pre-Stress on Black Schist, National Cheng Kung University, 2007, (in traditional Chinese).

[15] S. Zhan, Investigating the Laboratory Experiments to Estimate Pre-Stress on Changchikeng Sandston, National Cheng Kung University, 2008, (in traditional Chinese).
[16] H. Lin, J. Wu, and D. Lee, "Evaluating the pre-stress of MuShan sandstone using acoustic emission and deformation rate analysis," in In-situ rock stress, pp. 215-222, Taylor \& Francis London, 2006.

[17] B. Chen, S. Zhang, Y. Li, Z. Li, and H. Zhou, "Physical simulation study of crack propagation and instability information discrimination of rock-like materials with faults," Arabian Journal of Geosciences, vol. 13, no. 18, 2020.

[18] J. Chen, J. Zhao, S. Zhang, Y. Zhang, F. Yang, and M. Li, “An experimental and analytical research on the evolution of mining cracks in deep floor rock mass," Pure and Applied Geophysics, vol. 177, pp. 5325-5348, 2020.

[19] C. Zhu, M. He, M. Karakus, X. Cui, and Z. Tao, "Investigating toppling failure mechanism of anti-dip layered slope due to excavation by physical modelling," Rock Mechanics and Rock Engineering, vol. 53, pp. 5029-5050, 2020.

[20] E. Eberhardt, D. Stead, B. Stimpson, and R. S. Read, "Identifying crack initiation and propagation thresholds in brittle rock," Canadian Geotechnical Journal, vol. 35, no. 2, pp. 222-233, 1998.

[21] K. Tamaki, K. Yamamoto, T. Furuta, and H. Yamamoto, “35. An experiment of in-situ stress estimation on basaltic rock core samples from hole 758A, Ninetyeast Ridge, Indian Ocean," Journal of Infectious Diseases, vol. 208, no. 3, pp. 425-432, 1991.

[22] K. Yamamoto and T. Hirasaw, "An experimental and theoretical study of inelastic deformation of brittle rocks under cyclic uniaxial loading," Geological Survey of Japan, vol. 22, 1990.

[23] M. Seto, E. Villaescusa, M. Utagawa, and K. Katsuyama, "In situ stress evaluation from rock cores using AE method and DRA," Shigen-to-Sozai, vol. 114, no. 12, pp. 845-855, 1998.

[24] E. Villaescusa, M. Seto, and G. Baird, "Stress measurements from oriented core," International Journal of Rock Mechanics and Mining Sciences, vol. 39, no. 5, pp. 603-615, 2002.

[25] S. Hunt, A. Meyers, V. Louchnikov, and K. Oliver, "Use of the DRA technique, porosimetry and numerical modelling for estimating the maximum in-situ stress in rock from core," South African Institute of Mining \& Metallurgy, vol. 37, no. 1, pp. 17-22, 2003.

[26] H. Wang, L. Tang, X. Ren, A. Yang, and Y. Niu, "Mechanism of rock deformation memory effect in low stress region and its memory fading," Rock and Soil Mechanic, vol. 4, pp. 1007-1014, 2014, (in Chinese).

[27] H. J. Wang, A. V. Dyskin, A. Hsieh, and P. Dight, "The mechanism of the deformation memory effect and the deformation rate analysis in layered rock in the low stress region," Computers and Geotechnics, vol. 44, pp. 83-92, 2012.

[28] E. C. David, N. Brantut, A. Schubnel, and R. W. Zimmerman, "Sliding crack model for nonlinearity and hysteresis in the uniaxial stress-strain curve of rock," International Journal of Rock Mechanics and Mining Sciences, vol. 52, pp. 9-17, 2012.

[29] M. Basista and D. Gross, "The sliding crack model of brittle deformation: an internal variable approach," International Journal of Solids and Structures, vol. 35, no. 5-6, pp. 487509, 1998.

[30] H. J. Wang, L. Tang, X. H. Ren, L. W. Zhong, F. A. Si, and A. Hsieh, "Rock deformation memory effect: applications, experiments and theories," Chinese Journal of Geotechnical Engineering, vol. 40, no. 9, pp. 1-12, 2018, (in Chinese).

[31] R. Ulusay, The ISRM suggested methods for rock characterization, testing and monitoring: 2007-2014, Springer, 2014. 
[32] H. Wang, A. Dyskin, and E. Pasternak, "Comparative analysis of mechanisms of 3-D brittle crack growth in compression," Engineering Fracture Mechanics, vol. 220, p. 106656, 2019.

[33] R. L. Salganik, "Mechanics of bodies with many cracks," Mechanics of Solids, vol. 4, no. 8, pp. 135-143, 1973.

[34] R. L. Salganik, Overall effects due to cracks and crack-like defects, Springer Netherlands, 1982.

[35] J. H. Wu and S. C. Jan, "Experimental validation of core-based pre-stress evaluations in rock: a case study of Changchikeng sandstone in the Tseng-wen reservoir transbasin water tunnel," Bulletin of Engineering Geology and the Environment, vol. 69, no. 4, pp. 549-559, 2010. 